\title{
(2) OPEN ACCESS \\ Evidence base for point-of-care ultrasound (POCUS) for diagnosis of skull fractures in children: a systematic review and meta-analysis
}

\author{
Georgios Alexandridis 이 , ${ }^{1,2}$ Eva W Verschuuren, ${ }^{2}$ Arthur V Rosendaal, ${ }^{2}$ \\ Danny A Kanhai ${ }^{3}$
}

\section{Handling editor Jason E Smith}

- Additional material is published online only. To view please visit the journal online (http://dx.doi.org/10.1136/ emermed-2020-209887).

${ }^{1}$ Emergency Medicine, Erasmus Medical Center, Rotterdam, Zuid-Holland, The Netherlands 2Emergency Medicine,

Franciscus Gasthuis en Vlietland Rotterdam, Zuid-Holland, The Netherlands

${ }^{3}$ Pediatrics, Franciscus Gasthuis en Vlietland, Rotterdam, ZuidHolland, The Netherlands

\section{Correspondence to} Dr Georgios Alexandridis, Emergency Medicine, Erasmus Medical Center, Rotterdam, Zuid-Holland, Netherlands; g.alexandridis@erasmusmc.nl

Received 30 April 2020 Revised 6 October 2020 Accepted 7 October 2020
Check for updates

(C) Author(s) (or their employer(s)) 2020. Re-use permitted under CC BY. Published by BMJ.

\section{To cite: Alexandridis $\mathrm{G}$,} Verschuuren EW,

Rosendaal AV, et al. Emerg Med J Epub ahead of print: [please include Day Month Year]. doi:10.1136/ emermed-2020-209887

\section{ABSTRACT}

Background Blunt head trauma is a common presentation to emergency departments (EDs). Identifying skull fractures in children is important as they are known factor of risk for traumatic brain injury (TBI). Currently, CT is the reference standard for diagnosing skull fractures and TBIs in children. Identifying skull fractures with point-of-care ultrasound (POCUS) may help risk-stratify children for TBI following blunt trauma. The purpose of this study is to evaluate the sensitivity, specificity, positive predictive value and negative predictive value of POCUS in identifying skull fractures in children.

Methods A systematic search was performed on 17 July 2020 in Ovid Medline, Cochrane Library, Google Scholar, Web of Science and Embase. Prospective studies reporting skull fractures diagnosed with ultrasound in children younger than 18 years due to blunt head injury were included. Studies that did not confirm the fracture with $\mathrm{CT}$ were excluded. The quality of studies was evaluated using the QUADAS-2 tool. Data were extracted from the eligible studies to calculate outcomes such as sensitivity and specificity; when possible overall outcomes were calculated.

Results Seven studies were included. All eligible studies included patients for whom the decision to perform a CT scan was made in advance. Overall, the included studies demonstrated low risk of bias or had minor concerns regarding risk of bias. The pooled data $(n=925)$ demonstrated a sensitivity of $91 \%$, specificity of $96 \%$, positive predictive value of $88 \%$ and negative predictive value of $97 \%$.

Conclusion The included studies demonstrate minor methodological limitations. Overall, the evidence suggests that POCUS is a valid option for diagnosing skull fractures in children visiting the ED after blunt head injury.

\section{INTRODUCTION}

Head injuries in children are a common presentation to emergency departments (EDs) point-of-care ultrasounds (POCUS). The Centers for Disease Control and Prevention in the USA reported 749000 ED visits for injury to the head in children under the age of 15 years old in $2016 .{ }^{1}$ Up to $8 \%$ of children aged 3-17 years old have had a significant head injury in their lifetime, ${ }^{2-6}$ and it is one of the leading causes of mortality in children worldwide. ${ }^{3}$ Severely head-injured children are in general easily identified and treated. However, children who appear to have a low risk for traumatic brain injury

\section{Key messages}

What is already known on this subject

- Skull fractures are associated with traumatic brain injury; subsequently, clinical decision algorithms have been developed for head injured children that incorporate clinical suspicion for skull fractures.

- $\mathrm{CT}$ is the reference standard for diagnosing skull fractures and traumatic brain injuries; however, $\mathrm{CT}$ exposes children to radiation.

- Point-of-care ultrasound is a rapid and noninvasive diagnostic tool that has been used to identify skull fractures.

\section{What this study adds}

- This systematic review reveals that the included studies have minor methodological limitations and that point-of-care ultrasound has a high sensitivity and specificity to identify skull fractures in children with blunt head injuries.

- Point-of care-ultrasound could serve as an adjunct to increase the accuracy of clinical decision rules regarding using $\mathrm{CT}$ scans after head trauma in children; future research is necessary to define this role.

(TBI) may still have clinically important injury. ${ }^{2}$ POCUS may have a potential role in the evaluation of low-risk paediatric patients, to identify skull fractures and subsequent TBIs.

Clinical decision algorithms have been developed to identify head-injured children with TBI (eg, Pediatric Emergency Care Applied Research Network [PECARN], Canadian Assessment of Tomography for Childhood Head injury [CATCH], National Institute for Health and Care Excellence [NICE] Head Injury guideline or Children's Head injury ALgorithm for prediction of Clinically Important Events [CHALICE]). ${ }^{27-9}$ Most of the clinical decision algorithms include clinical suspicion of a skull fracture because the presence of skull fracture increases the likelihood of an intracranial injury fourfold. ${ }^{24810-13}$ Furthermore, TBI in the absence of skull fracture is rare in the paediatric population. ${ }^{14}$ The reported rate of skull fracture in children with blunt head trauma ranges from $16 \%$ to $63 \% .{ }^{11} 1415$ In addition, infants with skull fractures rarely present without local signs of head injury on physical examination. ${ }^{15} 16$ The diagnostic standard 
tool to detect TBI is CT. CT exposes children to radiation that may increase lifetime risk of malignancy. ${ }^{15-19}$ Also, it has been demonstrated that low doses of ionising radiation to the brain in infancy may influence cognitive ability in adulthood. ${ }^{20}$ Occasionally sedation is needed during the diagnostic study to minimise motion artefacts; sedation is also associated with the risk of adverse respiratory events including desaturation and the need for airway intervention. ${ }^{21}$ The use of CT scanning also adds to the costs of healthcare. ${ }^{22}$

'Mild head injury' patients are, according to the Head Injury Severity Scale classification, initially conscious at first assessment (GCS score 14-15), may have had a brief loss of consciousness or amnesia, but do not have any focal neurological deficits on admission. ${ }^{23}$ In mild head-injured children ultrasound might be utilised as a diagnostic tool for identifying skull fracture in children that may otherwise undergo a head CT. ${ }^{24-26}$

POCUS has become an integral part of emergency medicine practice. It is a rapid, non-invasive and inexpensive diagnostic tool that does not carry the risk of radiation in comparison to CT. ${ }^{27}$ Furthermore, in children who are more anxious and easily overstimulated, POCUS may be used by the attending physician at the bedside.

Identification of skull fractures in children is clinically relevant because these fractures may need surgical intervention irrespective of the presence of TBI. ${ }^{28}$ Skull fractures could be associated with non-accidental trauma, and physicians should always consider this potential association. ${ }^{29}$ In addition, skull fractures may need follow-up because linear fractures may predispose children to uncommon but serious complications such as expanding fractures or leptomeningeal cysts. ${ }^{3031}$

Clinicians must weigh the risk of missing a clinically important skull fracture and potentially associated TBI and the risks associated with performing a CT. As children with TBI can be asymptomatic, it remains challenging to successfully identify children at very low risk for TBI and safely manage them without performing a CT scan. However, if it is possible to rule out skull fractures utilising POCUS with high sensitivity, then it is less likely that there is an associated TBI. This may reduce the number of CT scans performed. Also, in hospitals where CT is not readily available POCUS may be helpful in risk stratification and subsequent transport to another facility.

This systematic review evaluates the test characteristics of POCUS in identifying skull fractures in children that present with blunt head injury in the ED.

\section{MATERIALS AND METHODS}

The Preferred Reporting Items for Systematic Reviews and Meta-Analyses guideline was used to conduct this review. ${ }^{32}$ Prior to performing this review, a protocol was developed (see online supplemental A). Consensus was reached among all authors on search syntax, inclusion and exclusion criteria, and the criteria for the assessment of validity and relevance in the identified articles.

\section{Search strategy}

A search was conducted on 17 July 2020 using the search engines Ovid Medline, Cochrane Library, Google Scholar, Web of Science and Embase. The search syntax encompassed 'skull', 'ultrasound', 'child' and 'fracture' (including their respective synonyms). Online supplemental B contains an overview of the complete search syntax. All articles which met the search terms were exported from the search engines to EndNote X9 (Clarivate Analytics, Philadelphia, Pennsylvania, USA).

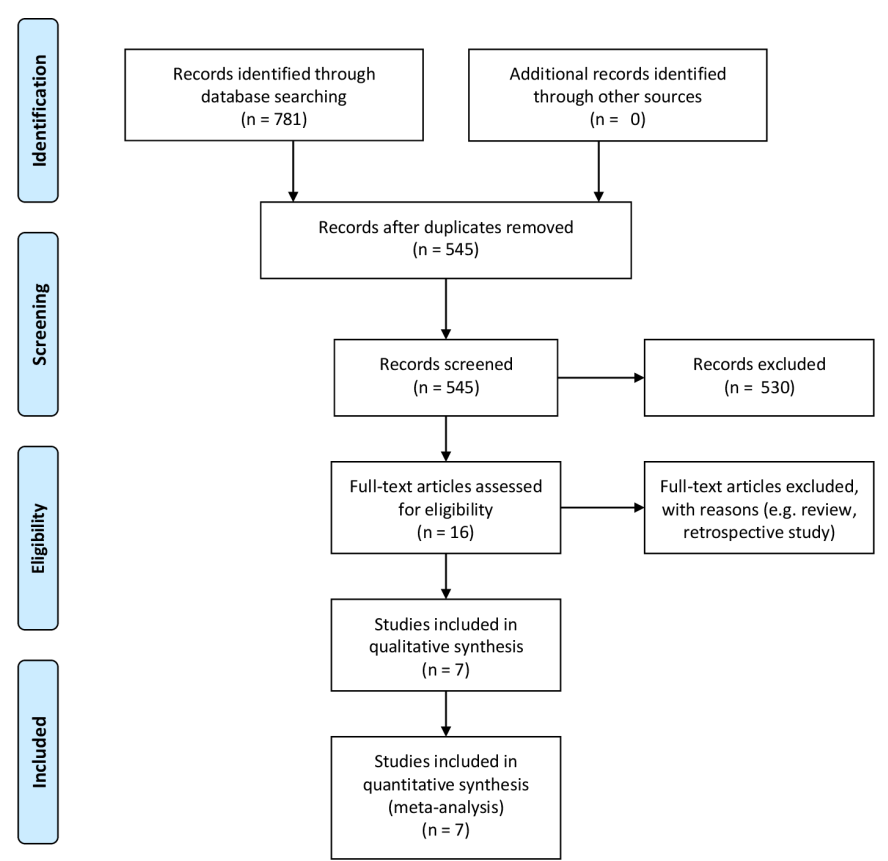

Figure 1 Flow-chart of search strategy and selection

\section{Selection}

Duplicates were excluded. We analysed all articles evaluating the outcome 'skull fracture'. Prospective studies written in English, German, French and Dutch that studied children with blunt head injury who visited the ED were included. Based on the inclusion criteria (figure 1), two reviewers (GA and EV) independently screened the titles and later the abstracts of eligible articles. Review articles, conference abstracts and case reports were excluded. The full text of the remaining articles was screened independently by two reviewers (EV and GA). Additionally, references in review articles were screened using the same criteria.

\section{Critical appraisal}

The quality of the individual studies was evaluated using the Quality Assessment of Diagnostic Accuracy Studies 2 (QUADAS-2) tool. ${ }^{33}$ This tool aids in evaluating the quality of primary diagnostic accuracy studies. It consists of four key domains; patient selection, index test, reference standard and flow and timing. Each domain is assessed in terms of the risk of bias, as 'low', 'high' or 'unclear'. Signalling questions are provided to help in judgement on the risk of bias. An overall judgement per study was given. If a study is judged as 'low' on all domains relating to validity than the overall judgement for that particular study was 'low risk of bias'; when one or more domains in validity was judged as 'unclear' or 'high' than that particular study was considered to be 'at risk of bias'. ${ }^{33}$

Three authors (GA, EV and AVR) independently evaluated the quality of the eligible studies. In case of disagreements in the critical appraisal, consensus was reached through discussion.

\section{Data extraction and statistical analysis}

Two authors extracted data separately from the eligible studies (EV and GA). The following data were extracted: year of publication, study characteristics, baseline population characteristics, country and data on the test results. When possible, the data of the studies was pooled to calculate overall characteristics. A fixed-effect model was used to compute pooled sensitivity and 
Table 1 Critical appraisal

\begin{tabular}{|c|c|c|c|c|c|c|c|c|c|}
\hline & \multirow[b]{2}{*}{ Study design } & \multicolumn{2}{|c|}{ Relevance (applicability) } & \multicolumn{6}{|c|}{ Validity (risk of bias) } \\
\hline & & Domain & $\begin{array}{l}\text { Reference } \\
\text { standard }\end{array}$ & $\begin{array}{l}\text { Patient } \\
\text { selection }\end{array}$ & Index test & $\begin{array}{l}\text { Reference } \\
\text { standard }\end{array}$ & $\begin{array}{l}\text { Flow and } \\
\text { timing }\end{array}$ & Remarks & $\begin{array}{l}\text { Overall risk } \\
\text { of bias }\end{array}$ \\
\hline Weinberg $^{36}$ & $\begin{array}{l}\text { Prospective observational } \\
\text { study }\end{array}$ & $\begin{array}{l}\text { Age }<25 \\
\text { years, urban } \\
\text { centre. }\end{array}$ & СT & High & Low & Low & Unclear & $\begin{array}{l}\text { Not only skull } \\
\text { fractures were } \\
\text { assessed. } \\
\text { Convenience } \\
\text { Sample. } \\
\text { Unclear interval } \\
\text { between POCUS } \\
\text { and CT }\end{array}$ & $\begin{array}{l}\text { At risk of } \\
\text { bias }\end{array}$ \\
\hline Riera $^{37}$ & $\begin{array}{l}\text { Prospective observational } \\
\text { study }\end{array}$ & $\begin{array}{l}\text { Age }<18 \\
\text { years, } \\
\text { Tertiary care } \\
\text { centre and } \\
\text { trauma level } \\
\text { one centre. }\end{array}$ & CT & High & Low & Low & Low & $\begin{array}{l}\text { Convenience } \\
\text { sample }\end{array}$ & $\begin{array}{l}\text { At risk of } \\
\text { bias }\end{array}$ \\
\hline Parri $i^{35}$ & $\begin{array}{l}\text { Prospective observational } \\
\text { study }\end{array}$ & $\begin{array}{l}\text { Age }<18 \\
\text { years. }\end{array}$ & CT & Low & Low & Low & Low & - & $\begin{array}{l}\text { Low risk of } \\
\text { bias }\end{array}$ \\
\hline Rabiner $^{38}$ & $\begin{array}{l}\text { Prospective observational } \\
\text { study }\end{array}$ & $\begin{array}{l}\text { Age }<21 \\
\text { years, trauma } \\
\text { level two } \\
\text { centre. }\end{array}$ & CT & High & Low & Low & Low & $\begin{array}{l}\text { Convenience } \\
\text { sample }\end{array}$ & $\begin{array}{l}\text { At risk of } \\
\text { bias }\end{array}$ \\
\hline $\mathrm{Choi}^{39}$ & $\begin{array}{l}\text { Prospective observational } \\
\text { study }\end{array}$ & $\begin{array}{l}\text { Age }<4 \text { years, } \\
\text { tertiary care } \\
\text { centre and } \\
\text { trauma level I } \\
\text { centre. }\end{array}$ & CT & High & Low & Low & Low & $\begin{array}{l}\text { Convenience } \\
\text { sample }\end{array}$ & $\begin{array}{l}\text { At risk of } \\
\text { bias }\end{array}$ \\
\hline Parri ${ }^{40}$ & $\begin{array}{l}\text { Multicentre prospective } \\
\text { observational study }\end{array}$ & Age $<2$ years. & CT & High & Low & Low & Low & $\begin{array}{l}\text { Convenience } \\
\text { sample }\end{array}$ & $\begin{array}{l}\text { At risk of } \\
\text { bias }\end{array}$ \\
\hline Masaeli $^{34}$ & $\begin{array}{l}\text { Prospective cross- } \\
\text { sectional study }\end{array}$ & $\begin{array}{l}\text { Age }<18 \\
\text { years, tertiary } \\
\text { care centre. }\end{array}$ & CT & Low & Low & Low & Low & - & $\begin{array}{l}\text { Low risk of } \\
\text { bias }\end{array}$ \\
\hline
\end{tabular}

POCUS, point-of-care ultrasound.

specificity. The homogeneity of the studies was determined with visual inspection; the homogeneity in age and trauma mechanism were analysed. $\mathrm{I}^{2}$ was used to evaluate the between-study heterogeneity throughout the random-effects meta-analysis; Q-test was used to determine whether the heterogeneity was statistically significant. Publication bias was assessed through Egger's regression test. Comprehensive Meta-Analysis V.3 (Biostat, Englewood, New Jersey, USA) was used to perform all statistical testing.

\section{RESULTS}

\section{Search strategy and selection}

The search resulted in 781 articles. After exclusion of duplicates 545 articles remained for title and abstract screening. Full text and reference assessment was completed for 16 articles; afterwards seven articles were excluded because they were reviews and two because they were retrospective studies (figure 1). We manually checked the references of the reviews; our search had identified all studies referenced in these reviews.

\section{Critical appraisal}

Seven studies were included; two studies had a low risk of bias. $^{3435}$ Five studies were at risk of bias in the domain 'patient selection'. ${ }^{36-40}$ One study was at risk of bias in the domain 'flow and timing' because the time interval between POCUS and CT was unclear. ${ }^{36}$ An overview is presented in table 1.
All studies had a prospective observational study design and included patients with head trauma. In all eligible studies, the decision to perform a CT was made in advance.

\section{Data extraction}

The results of data extraction are shown in tables 2 and 3 .

\section{Statistical analysis}

Visual inspection showed that two studies had a substantially higher percentage of skull fractures ${ }^{35}{ }^{40}$; subsequently, we divided the studies in two groups. In one group, the two studies with a high percentage of fractures were pooled and the other group contained the five studies with a low percentage of fractures. Furthermore, two studies included patients aged 18 years or older; subsequently, to assess the influence on outcome results a separate analysis was executed in which these two studies were excluded. $^{3638}$ Afterwards, the outcome results per group were calculated (see table 3 ). In the overall pooled data $\mathrm{I}^{2}$ was 32.14 and $Q$ was 8.84. The Egger's regression intercept did not demonstrate a publication bias $(\mathrm{p}=0.313)$.

\section{Patient characteristics}

All studies included patients from the ED. The number of patients included in the studies ranged from 21 to 538. Three studies included patients up to 18 years old. ${ }^{343537}$ The study of Parri et $a l^{40}$ included children under the age of 2 and the 


\section{Systematic review}

Table 2 Study and population characteristics

\begin{tabular}{|c|c|c|c|c|c|c|c|}
\hline & \multicolumn{4}{|c|}{ Study characteristics } & \multicolumn{3}{|l|}{ Population characteristics } \\
\hline & $\begin{array}{l}\text { No of patients } \\
(\mathrm{N}=)\end{array}$ & Country & Training & Experience & Age & $\begin{array}{l}\text { Trauma mechanism } \\
(\%)\end{array}$ & $\begin{array}{l}\text { Incidence of fractures } \\
(\%)\end{array}$ \\
\hline Weinberg $^{36}$ & 21 & USA & 1 hour & NR & Median 13 y & NR & 10 \\
\hline Riera $^{37}$ & 40 & USA & NR & $1 \mathrm{mo}$ to $10 \mathrm{y}$ & Median 2 y (2 mo to 17 y) & NR & 15 \\
\hline Parri $^{35}$ & 55 & Italy & 1 hour & 16 hours & Mean 5 y ( 2 mo to 14 y) & Fall (71) & 64 \\
\hline Rabiner $^{38}$ & 69 & USA & 1 hour & variable & Mean 7 y (7 days to 21 y) & NR & 12 \\
\hline Choi $^{39}$ & 87 & South Korea & 1 hour & variable & $\begin{array}{l}\text { Mean } 21 \text { mo ( } 2 \text { mo to } \\
48 \mathrm{mo})\end{array}$ & Fall $<0.9 \mathrm{~m}(67)$ & 15 \\
\hline Parri $^{40}$ & 115 & Italy, USA & $\begin{array}{l}\text { Two videos and } \\
\text { skills }\end{array}$ & variable & Mean 8 mo (SD 6) & $\begin{array}{l}\text { Fall from elevation } \\
\text { (75) }\end{array}$ & 77 \\
\hline Masaeli ${ }^{34}$ & 538 & Iran & $\begin{array}{l}\text { Theory and skills } \\
\text { workshop }\end{array}$ & NR & $\begin{array}{l}\text { Mean } 6 \text { y (SD 5, range } \\
0-18 \text { y) }\end{array}$ & $\begin{array}{l}\text { Fall (44), motor } \\
\text { vehicle accidents (15), } \\
\text { other (41) }\end{array}$ & 14 \\
\hline
\end{tabular}

mo, months; NR, not reported; $y$, year.

Table 3 Results

\begin{tabular}{|c|c|c|c|c|c|c|c|c|}
\hline & \multirow{3}{*}{$\begin{array}{l}\text { No of patients } \\
(\mathrm{N}=)\end{array}$} & \multirow{3}{*}{$\begin{array}{l}\text { Sensitivity } \\
\% \\
(95 \% \mathrm{Cl})\end{array}$} & \multirow{3}{*}{$\begin{array}{l}\text { Specificity } \\
\% \\
(95 \% \mathrm{Cl})\end{array}$} & \multirow{3}{*}{$\begin{array}{l}\begin{array}{l}\text { Positive } \\
\text { predictive value }\end{array} \\
\% \\
(95 \% \mathrm{Cl}) \\
\end{array}$} & \multirow{3}{*}{$\begin{array}{l}\begin{array}{l}\text { Negative } \\
\text { predictive value }\end{array} \\
\% \\
(95 \% \mathrm{Cl})\end{array}$} & \multirow{3}{*}{$\begin{array}{l}\text { False-positive } \\
\mathrm{N}=\end{array}$} & \multirow{3}{*}{$\begin{array}{l}\text { False negative } \\
\mathrm{N}=\end{array}$} & \multirow[b]{3}{*}{ Risk of bias } \\
\hline & & & & & & & & \\
\hline & & & & & & & & \\
\hline \multicolumn{9}{|c|}{ High percentage of fractures } \\
\hline Parri $^{35}$ & 55 & $100(88$ to 100$)$ & 95 (73 to 100$)$ & 97 (84 to 100$)$ & 100 (79 to 100$)$ & $\begin{array}{l}\text { 1: Non calcified } \\
\text { suture ipsilateral } \\
\text { to trauma }\end{array}$ & 0 & Low risk of bias \\
\hline Parri $^{40}$ & 115 & 91 (82 to 96) & 85 (65 to 95$)$ & 95 (88 to 98$)$ & 74 (55 to 87$)$ & 4: Not reported & $\begin{array}{l}\text { 8: Fracture not } \\
\text { underneath area } \\
\text { that was imaged }\end{array}$ & At risk of bias \\
\hline \multicolumn{9}{|c|}{ Low percentage of fractures } \\
\hline Weinberg $^{36 *}$ & 21 & 100 (20 to 100$)$ & 100 (79 to 100$)$ & $100(20$ to 100$)$ & 100 (79 to 100$)$ & 0 & 0 & At risk of bias \\
\hline Riera $^{37}$ & 40 & 67 (24 to 94) & 97 (83 to 100) & 80 (30 to 99) & 94 (79 to 99) & 1: Not reported & $\begin{array}{l}\text { 1: Not reported } \\
\text { 1: No cooperation } \\
\text { of patient }\end{array}$ & At risk of bias \\
\hline Rabiner $^{38 \text { * }}$ & 69 & 88 (47 to 99) & 97 (88 to 99) & 78 (40 to 96$)$ & 98 (90 to 100$)$ & $\begin{array}{l}\text { 1: Novice error } \\
\text { 1: CT no fracture, } \\
\text { possibly false } \\
\text { negative as the } \\
\text { sonographers seem } \\
\text { to be convinced } \\
\text { that it truly was a } \\
\text { fracture }\end{array}$ & $\begin{array}{l}\text { 1: Fracture } \\
\text { adjacent to } \\
\text { haematoma in the } \\
\text { area that was not } \\
\text { imaged }\end{array}$ & At risk of bias \\
\hline $\mathrm{Choi}^{39}$ & 87 & 77 (46 to 94$)$ & 100 (94 to 100$)$ & 100 (66 to 100$)$ & 96 (88 to 99$)$ & 0 & $\begin{array}{l}\text { 2: Difficult } \\
\text { evaluation in area } \\
\text { of orbital wall and } \\
\text { skull base } \\
\text { 1: Fracture not } \\
\text { in imaged area, } \\
\text { adjacent to } \\
\text { haematoma }\end{array}$ & At risk of bias \\
\hline Masaeli $^{34}$ & 538 & 92 (83 to 97) & 96 (94 to 97) & 79 (69 to 87$)$ & 99 (97 to 99) & 19: Not reported & 6: Not reported & Low risk of bias \\
\hline \multicolumn{9}{|l|}{ Pooled data } \\
\hline Overall pooled data & 925 & 91 (87 to 94) & 96 (94 to 97) & 88 (84 to 92 ) & 97 (95 to 98) & 27 & 20 & \\
\hline Pooled data A & 170 & 93 (87 to 97 ) & 89 (76 to 96$)$ & 96 (90 to 98$)$ & 84 (70 to 92$)$ & 5 & 8 & \\
\hline Pooled data B & 755 & 89 (81 to 94) & 97 (95 to 98) & 81 (73 to 88 ) & 98 (97 to 99) & 22 & 12 & \\
\hline Pooled data C & 720 & 92 (85 to 96 ) & 96 (95 to 98 ) & 85 (78 to 90$)$ & 98 (97 to 99) & 21 & 11 & \\
\hline Pooled data D & 835 & 91 (87 to 95$)$ & 96 (94 to 97$)$ & 88 (84 to 92 ) & 97 (95 to 98 ) & 25 & 19 & \\
\hline
\end{tabular}

Pooled data A (studies with a high percentage in fractures): Parri ${ }^{35}$ and Parri ${ }^{40}$.

Pooled data B (studies with a low percentage in fractures): Weinberg ${ }^{36}$, Riera $^{37}$, Rabiner $^{38}, \mathrm{Choi}^{39}$ and Masaeli ${ }^{34}$.

Pooled data C (studies with a low percentage in fractures, excluded the studies that contained patients aged $>18$ years): Riera $^{37}$, Choi ${ }^{39}$ and Masaeli ${ }^{34}$.

Pooled data D (all studies, excluded the studies that contained patients aged $>18$ years): Riera ${ }^{37}$, Parri ${ }^{35}$, Parri $^{40}$, Choi ${ }^{39}$ and Masaeli ${ }^{34}$.

* Study that contained patients aged $>18$ years. 
study of Choi $e a \mathrm{l}^{39}$ children up to 4 years of age. ${ }^{39} 40$ One study included patients up to 21 years and another study up to 25 years old. $^{3638}$ Four studies reported a mean age between 8 months and 7 years. ${ }^{35}{ }^{38-40}$ Weinberg et al $^{36}$ reported a median age of 13 years, and Riera and $\mathrm{Chen}^{37}$ a median of 2 years.

Four studies included patients with minor head injury (GCS 14 or 15). ${ }^{34353940}$ Two studies did not report the GCS. ${ }^{36} 37$ Masaeli et $a l^{34}$ reported that $11 \%$ of the included children had a GCS lower than 15; this particular study excluded patients that had a GCS of 13 or lower. ${ }^{34}$ Rabiner et al ${ }^{38}$ reported a GCS below 15 in $12 \%$ of the included patients. ${ }^{38}$

Trauma mechanism was described in four studies; in up to $75 \%$ of the patients the mechanism of trauma was a fall. ${ }^{3435} 3940$ The percentage of fractures per study ranged from $10 \%$ to $77 \%$.

\section{Training and experience}

In all studies ultrasound was performed by emergency physicians or fellows. Four studies reported 1-hour training focused on ultrasonography of the skull..$^{35} 363839$ In two studies the clinicians were trained with videos and skills training. ${ }^{34}{ }^{40}$ In four studies the ultrasonographer had varying levels of experience. ${ }^{37-40}$ Two studies did not report the previous experience of the sonographers. ${ }^{34} 36$ One study reported that the sonographers had 16 hours of experience. ${ }^{35}$ Training and experience are summarised in table 2 .

\section{Diagnostic accuracy}

Sensitivity ranged from $67 \%$ to $100 \%$ and specificity from $85 \%$ to $100 \%$. The seven studies demonstrated a weighted percentage of skull fractures of $25 \%$. The overall pooled data $(n=925)$ demonstrated a sensitivity of $91 \%$, a specificity of $96 \%$, a positive predictive value of $88 \%$ and a negative predictive value of 97\% (see table 3).

The pooled results of studies with a high percentage of fractures were similar to those of the studies with a low percentage of fractures (pooled data A and B in table 3). Furthermore, the results were similar whether those over 18 were included or excluded. (pooled data B, C, D and overall pooled data). To illustrate the similarities, we created a paired forest plot for sensitivity and specificity (see figure 2).

\section{False positive results}

There were 27 false positive results (2.9\% of all scans). In 24 of these cases, the cause was not reported. Parri et $a l^{35}$ reported a false positive result due to a non-calcified ipsilateral suture. One case was the effect of a novice error, as the physician interpreted the ultrasound as positive, an expert sonographer interpreted the ultrasound as negative for fracture. ${ }^{38}$ Another case was interpreted during the initial POCUS imaging as positive for a fracture and during re-evaluation by an expert paediatric emergency

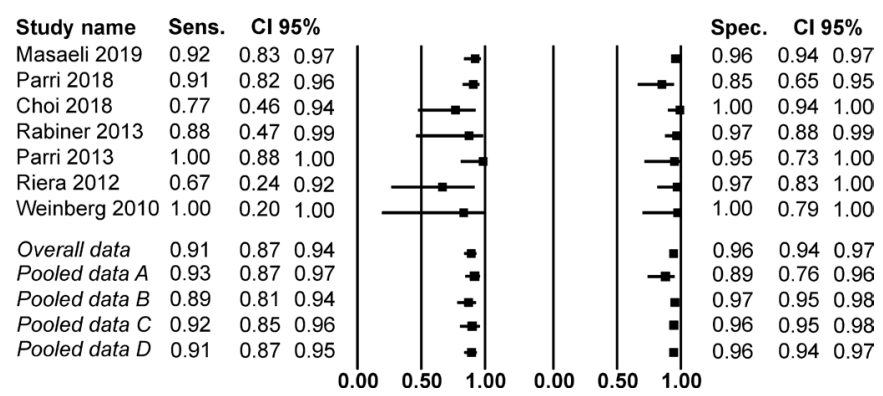

Figure 2 physician sonographer as a minimally displaced skull fracture; however, this fracture was not visualised by the CT scan. ${ }^{38}$

\section{False negative results}

Twenty false negative cases were reported (2.2\% of all scans). The majority of these false negatives $(n=10)$ were the consequence of the fracture being adjacent to a haematoma and not in the area that was imaged.

\section{DISCUSSION}

The aim of this study was to evaluate the test characteristics of POCUS in identifying skull fractures in children that presented in the ED with blunt head injury. The pooled data showed a high sensitivity, specificity and predictive values in the studies included. Our systematic review, therefore, demonstrates that POCUS of the skull can be useful in accurately identifying skull fractures in children with head injury.

While conducting this systematic review, another systematic review by Gordon et al $^{41}$ was published ${ }^{41}$; our findings are consistent with that review. Our review used a more extensive search, using more databases and including articles published in multiple languages. Subsequently, we identified an additional relevant study, which adds a substantial number of patients to our pooled data. Furthermore, additional subanalyses were performed to evaluate whether these subgroups (studies that included patients over the age of 18 years, and high vs low percentage of fractures per group) affected the results.

POCUS could serve as an adjunct to increase the accuracy of clinical decision rules regarding the use of CT scans after head trauma in children. POCUS is fast and may be performed at bedside, which provides benefits of rapid identification of skull fracture, that could help to prioritise patients. Furthermore, POCUS may help with the decision to transfer the patient to another facility. Moreover, no pharmacological sedation is needed for this diagnostic tool.

The identified studies in this review show possible limitations in applicability. First, all studies had varying experience in POCUS performers (see table 2). Because the interpretation of POCUS is operator dependent, this may have affected the diagnostic accuracy. ${ }^{37}$ Rabiner $e t a l^{38}$ reported that the interobserver agreement was $\kappa=0.86$ (95\% CI 0.67 to 1.0 ). The other studies did not report the inter-observer agreement among physicians that performed POCUS.

Second, the range in percentage of fractures per study was wide $(10 \%-77 \%)$; potentially affecting the test accuracy. Parri et $a l^{35}$ and Parri et $a l^{40}$ had a higher percentage of fractures. The younger age of the population studied may have influenced the incidence; children under the age of 2 tend to be at higher risk of skull fractures. ${ }^{41}$ Although there was overall a high sensitivity and specificity of the test, this pretest probability has to be for accounted for. The study of Choi $e t a l^{39}$ did not apply clinical decision rules and this factor possibly led to a lower number of fractures; this could also have occurred in the other studies with a relatively low number of fractures. ${ }^{36-38}$

Third, two studies included patients older than 18 years. ${ }^{36} 38$ For both studies, insufficient data regarding the proportion of patients aged 18 years or above was provided. However, it seems unlikely that a significant number of patients was older than 18 years because the reported mean age was 7 years in one study and in the other studies the reported median age 13 years; in addition, the subanalysis showed similar results. Hence, the influence seems to be minor. ${ }^{3638}$ 
Fourth, many studies did not report the mechanism of injury; it seems likely that presence of a skull fracture may be associated with the mechanism. Furthermore, not all the studies reported GCS. It is unclear to what extent this influenced the results.

Finally, only two studies were multicentre. ${ }^{34} 40$ Three studies were conducted in a tertiary care centre, which may have influenced the population studied; in general, such centres receive more severe injured patients. ${ }^{34} 37394243$

Five of the seven studies were at risk of bias because they studied a convenience sample; this might lead to underrepresentation of subgroups. ${ }^{36-40}$

The study of Weinberg et $a l^{36}$ has a remarkably high sensitivity and specificity of $100 \%$. This may be explained due to the relatively small sample size of 21 patients that might overestimate the results. Also, the study is at risk of biases that might influence the results positively.

The study of Riera and Chen ${ }^{37}$ has a notable lower sensitivity for identifying skull fractures; this lower sensitivity was attributed to the lower number of skull fractures in the studied population. ${ }^{37}$ Several studies demonstrated that not all skull fractures were located beneath the haematoma; those studies only imaged the haematoma area with ultrasonography. By imaging a larger part of the skull these missed fractures may have been avoided.

Two 'false negative' fractures were located in a position where ultrasound evaluation is difficult, for example, orbital wall and skull base. It might be advised to reconsider imaging in children that present with a haematoma at sites that are more challenging to ultrasound or when interpretation of the ultrasound is difficult. It is key to minimise false negatives, because of the association of skull fractures with TBI. Perhaps with better ultrasonography techniques in addition to better training, false negatives may be avoided in the future. However, none of the studies reported adverse events in the cases with a missed fracture.

Suture planes can complicate the identification of fractures, and could lead to false positive results. However, evaluation of the contralateral anatomy or tracking suture lines to the fontanelle may aid in this, and knowledge of suture line anatomy is essential. $^{35} 3738$

Our search is limited to articles written in English, Dutch, German or French. During the abstract screening, none of the identified articles were excluded on language. The included studies all had positive results in favour of POCUS; it is possible that studies with other outcomes did not get published, therefore, creating publication bias. In any literature review, there is the possibility of publication bias; however, the Egger's regression intercept did not demonstrate this particular bias.

This systematic review shows that POCUS proves to be a valid option for ruling out skull fractures in children visiting the ED after blunt head injury, although methodological limitations could be debated in several included studies.

We recommend consideration of POCUS in patients that meet no other major or multiple minor criteria for CT scan than a clinical suspected skull fracture, or when a skull fracture cannot be excluded; consequently, when no fracture is identified, a CT scan might not be needed. Therefore, to use POCUS to rule out a skull fracture could potentially reduce the utilisation of CT and unnecessary exposure of children to ionising radiation. The aim of POCUS is not to detect TBI, but it can identify skull fracture which is an important predictor of TBI. ${ }^{44}$

Future research is necessary to define the role of POCUS in risk stratification for TBI and applicability in clinical prediction rules. Furthermore, additional research is needed to define whether extending the imaged area with POCUS to not only the area of haematoma but also adjacent areas will further improve the results.

Acknowledgements We would like to acknowledge Wichor M. Bramer (biomedical information specialist) for his help in creating the search syntax; Erwin Birnie (statistician) for evaluating the method of this review; Vanessa Brown (emergency physician) and Jerome Raaijmakers (radiologist) for critically reviewing this review.

Contributors GA: designed the review, participated in identifying eligible studies, performed the statistical analysis and has participated in writing the manuscript. EV: participated in identifying eligible studies, extracted data and has participated in writing the manuscript. AVR: subject matter expert, reviewed the manuscript and aided with the interpretation of the results. DAK: subject matter expert, reviewed the manuscript and gave aid with the statistical analysis and interpretation of the results.

Funding The authors have not declared a specific grant for this research from any funding agency in the public, commercial or not-for-profit sectors.

Competing interests None declared.

\section{Patient consent for publication Not required.}

Provenance and peer review Not commissioned; externally peer reviewed.

Supplemental material This content has been supplied by the author(s). It has not been vetted by BMJ Publishing Group Limited (BMJ) and may not have been peer-reviewed. Any opinions or recommendations discussed are solely those of the author(s) and are not endorsed by BMJ. BMJ disclaims all liability and responsibility arising from any reliance placed on the content. Where the content includes any translated material, BMJ does not warrant the accuracy and reliability of the translations (including but not limited to local regulations, clinical guidelines, terminology, drug names and drug dosages), and is not responsible for any error and/or omissions arising from translation and adaptation or otherwise.

Open access This is an open access article distributed in accordance with the Creative Commons Attribution 4.0 Unported (CC BY 4.0) license, which permits others to copy, redistribute, remix, transform and build upon this work for any purpose, provided the original work is properly cited, a link to the licence is given, and indication of whether changes were made. See: https://creativecommons.org/ licenses/by/4.0/.

\section{ORCID iD}

Georgios Alexandridis http://orcid.org/0000-0003-2893-3104

\section{REFERENCES}

1 Rui P, Kang K, Ashman JJ. National Hospital ambulatory medical care survey: 2016 emergency department summary tables, 2016.

2 Kuppermann N, Holmes JF, Dayan PS, et al. Identification of children at very low risk of clinically-important brain injuries after head trauma: a prospective cohort study. The Lancet 2009;374:1160-70.

3 Black LI, Zammitti EP, Hoffman HJ, et al. Parental report of significant head injuries in children aged 3-17 years: United States, 2016. US Department of Health and Human Services, Centers for Disease Control and Prevention, 2018.

4 Schutzman SA, Greenes DS. Pediatric minor head trauma. Ann Emerg Med 2001;37:65-74.

5 Ponsky TA, Eichelberger MR, Cardozo E, et al. Analysis of head injury admission trends in an urban American pediatric trauma center. J Trauma 2005;59:1292-7.

6 Chaudhary S, Figueroa J, Shaikh S, et al. Pediatric falls ages 0-4: understanding demographics, mechanisms, and injury severities. Injury Epidemiology 2018;5:7.

7 NICE. Head injury: assessment and early management, 2019. Available: https://www. nice.org.uk/guidance/cg176 [Accessed July, 2020].

8 Osmond MH, Klassen TP, Wells GA, et al. Catch: a clinical decision rule for the use of computed tomography in children with minor head injury. Can Med Assoc J 2010;182:341-8.

9 Lyttle MD, Crowe L, Oakley E, et al. Comparing catch, chalice and PECARN clinical decision rules for paediatric head injuries. Emerg Med J 2012;29:785-94.

10 Dunning Jet al. A meta-analysis of variables that predict significant intracranial injury in minor head trauma. Arch Dis Child 2004;89:653-9.

11 Quayle KS, Jaffe DM, Kuppermann N, et al. Diagnostic testing for acute head injury in children: when are head computed tomography and skull radiographs indicated? Pediatrics 1997;99:E11.

12 Boran BO, Boran P, Barut N, et al. Evaluation of mild head injury in a pediatric population. Pediatr Neurosurg 2006;42:203-7.

13 Shane SA, Fuchs SM. Skull fractures in infants and predictors of associated intracranial injury. Pediatr Emerg Care 1997;13:198-203.

14 Greenes DS, Schutzman SA. Infants with isolated skull fracture: what are their clinical characteristics, and do they require hospitalization? Ann Emerg Med 1997;30:253-9.

15 Greenes DS, Schutzman SA. Clinical significance of scalp abnormalities in asymptomatic head-injured infants. Pediatr Emerg Care 2001;17:88-92. 
16 Trenchs V, Curcoy Al, Castillo M, et al. Minor head trauma and linear skull fracture in infants: cranial ultrasound or computed tomography? Eur J Emerg Med 2009;16:150-2.

17 Brenner DJ, Hall EJ. Computed tomography — an increasing source of radiation exposure. N Engl J Med 2007;357:2277-84.

18 Brenner D, Elliston C, Hall E, et al. Estimated risks of radiation-induced fatal cancer from pediatric CT. AJR Am J Roentgenol 2001;176:289-96.

19 Hennelly KE, Mannix R, Nigrovic LE, et al. Pediatric traumatic brain injury and radiation risks: a clinical decision analysis. J Pediatr 2013;162:392-7.

20 Hall Pet al. Effect of low doses of ionising radiation in infancy on cognitive function in adulthood: Swedish population based cohort study. BMJ 2004;328:19.

21 Sanborn PA, Michna E, Zurakowski D, et al. Adverse cardiovascular and respiratory events during sedation of pediatric patients for imaging examinations. Radiology 2005;237:288-94

22 Saiful Islam SM, Abru AF, Al Obaidani S, et al. Trends in CT Request and related outcomes in a pediatric emergency department. Oman Med J 2016;31:365-9.

23 Stein SC, Spettell C. The head injury severity scale (hisS): a practical classification of closed-head injury. Brain Inj 1995;9:437-44.

24 Patel DD, Blumberg SM, Crain EF. The utility of bedside ultrasonography in identifying fractures and guiding fracture reduction in children. Pediatr Emerg Care 2009:25:221-5

25 Cross KP, Warkentine FH, Kim IK, et al. Bedside ultrasound diagnosis of clavicle fractures in the pediatric emergency department. Acad Emerg Med 2010;17:687-93.

26 Lee $\mathrm{MH}$, Cha JG, Hong HS, et al. Comparison of high-resolution ultrasonography and computed tomography in the diagnosis of nasal fractures. J Ultrasound Med 2009:28:717-23.

27 Torloni MR, Vedmedovska N, Merialdi M, et al. Safety of ultrasonography in pregnancy: who systematic review of the literature and meta-analysis. Ultrasound Obstet Gynecol 2009;33:599-608.

28 Liu X-S, You C, Lu M, et al. Growing skull fracture stages and treatment strategy. J Neurosurg Pediatr 2012;9:670-5.

29 Joyce T, Huecker MR. Pediatric abusive head trauma (Shaken baby syndrome. StatPearls Treasure Island (FL: StatPearls Publishing LLC, 2018.

30 de P Djientcheu V, Njamnshi AK, Ongolo-Zogo P, et al. Growing skull fractures. Childs Nerv Syst 2006:22:721-5.
31 Vignes J-R, Jeelani NUO, Jeelani A, et al. Growing skull fracture after minor closedhead injury. J Pediatr 2007;151:316-8.

32 Moher D, Liberati A, Tetzlaff J. Preferred reporting items for systematic reviews and meta-analyses: the PRISMA statement. Ann Intern Med 2009:151:264-9.

33 Whiting PFet al. QUADAS-2: a revised tool for the quality assessment of diagnostic accuracy studies. Ann Intern Med 2011;155:529-36.

34 Masaeli M, Chahardoli M, Azizi S, et al. Point of care ultrasound in detection of brain hemorrhage and skull fracture following pediatric head trauma; a diagnostic accuracy study. Arch Acad Emerg Med 2019;7:e53.

35 Parri N, Crosby BJ, Glass C, et al. Ability of emergency ultrasonography to detect pediatric skull fractures: a prospective, observational study. J Emerg Med 2013;44:135-41.

36 Weinberg ER, Tunik MG, Tsung JW. Accuracy of clinician-performed point-of-care ultrasound for the diagnosis of fractures in children and young adults. Injury 2010:41:862-8.

37 Riera A, Chen L. Ultrasound evaluation of skull fractures in children: a feasibility study. Pediatr Emerg Care 2012:28:420-5.

38 Rabiner JE, Friedman LM, Khine $\mathrm{H}$, et al. Accuracy of point-of-care ultrasound for diagnosis of skull fractures in children. Pediatrics 2013;131:e1757-64.

39 Choi JY, Lim YS, Jang JH, et al. Accuracy of bedside ultrasound for the diagnosis of skull fractures in children aged 0 to 4 years. Pediatr Emerg Care 2020;36:e268-73.

40 Parri N, Crosby BJ, Mills L, et al. Point-Of-Care ultrasound for the diagnosis of skull fractures in children younger than two years of age. J Pediatr 2018;196:230-6.

41 Gordon I, Sinert R, Chao J. The utility of ultrasound in detecting skull fractures after pediatric blunt head trauma: systematic review and meta-analysis. Pediatr Emerg Care 2020. doi:10.1097/PEC.0000000000001958. [Epub ahead of print: 28 Feb 2020].

42 Glance LG, Osler TM, Mukamel DB, et al. Impact of trauma center designation on outcomes: is there a difference between level I and level II trauma centers? J Am Coll Surg 2012;215:372-8.

43 van der Sluijs R, Lokerman RD, Waalwijk JF, et al. Accuracy of pre-hospital trauma triage and field triage decision rules in children (P2-T2 study): an observational study. Lancet Child Adolesc Health 2020;4:290-8.

44 Schutzman SA, Barnes P, Duhaime A-C, et al. Evaluation and management of children younger than two years old with apparently minor head trauma: proposed guidelines. Pediatrics 2001:107:983-93. 